\title{
Concomitant Crown and Piece of Tray Ingestion: A Case Report
}

\author{
Yuh Baba ${ }^{\mathrm{a}, \mathrm{c}}$, Yasumasa Kato ${ }^{\mathrm{b}}$
}

\begin{abstract}
The ingestion of a foreign body is a complication often seen in the hospital emergency rooms. The dental university hospital, where instruments and products are manipulated in the mouth, is an environment of risk. Previously, accidental foreign body ingestion during a routine dental procedure was reported by different groups. However, ingestion of multiple foreign bodies during a routine dental impression procedure is uncommon. Here, we describe a clinical case of accidental ingestion of concomitant crown and piece of tray. Some clinical implications are discussed, mainly emphasizing the care needed to prevent such an accident.
\end{abstract}

Keywords: Multiple foreign bodies; Dental impression procedure

\section{Introduction}

The ingestion of a foreign body is a complication often seen in the hospital emergency rooms. The dental university hospital, where instruments and products are manipulated in the mouth, is an environment of risk [1]. Dental objects that have been swallowed include dental prostheses and endodontic instruments. Ninety percent of ingested foreign bodies pass through the gastrointestinal tract uneventfully. However, the ingestion of foreign body can sometimes cause serious complications [2]. Treatment depends on the type and size of the object and its location [3].

During dental treatment, we must be aware of practices that decrease the risk of accidentally swallowing an object. In the doctor's office, patients must be guided to prevent such occurrences.

Manuscript accepted for publication September 28, 2016

aDepartment of General Clinical Medicine, Ohu University, 31-1 Misumido Tomita-machi Koriyama City, Fukushima 963-8611, Japan

bepartment of Oral Function and Molecular Biology, Ohu University, 31-1 Misumido Tomita-machi Koriyama City, Fukushima 963-8611, Japan

${ }^{\mathrm{c} C}$ Corresponding Author: Yuh Baba, Department of General Clinical Medicine, Ohu University, 31-1 Misumido Tomita-machi Koriyama City, Fukushima 963-8611, Japan. Email: yuh_baba@hotmail.com

doi: http://dx.doi.org/10.14740/jmc2654w
Previously, accidental foreign body ingestion during a routine dental procedure was reported by different groups [13]. However, ingestion of multiple foreign bodies during a routine dental procedure is uncommon. The purpose of this article was to describe a clinical case of accidental ingestion of concomitant crown and piece of tray. Some clinical implications are discussed, mainly emphasizing the care needed to prevent such an accident.

\section{Case Report}

A 77-year-old Japanese man with no significant previous medical history presented at the emergency service of our hospital following the accidental ingestion of a crown during a routine dental impression procedure. His general condition was very good, without dyspnea, nausea, vomiting or abdominal pain. On examination, he was hemodynamically stable with no evidence of airway compromise, respiratory distress or abdominal tenderness. Pharyngolaryngo fiberscopic analysis revealed normal suggesting passage of the foreign body into the esophagus. On a plain abdominal X-ray study, there was suspicion of crown and something in the stomach (Fig. 1). An erect chest X-ray was normal (data not shown). Urgent esophago-gastro-duodenoscopy could retrieve the foreign body. And surprisingly, we recognized concomitant crown and piece of

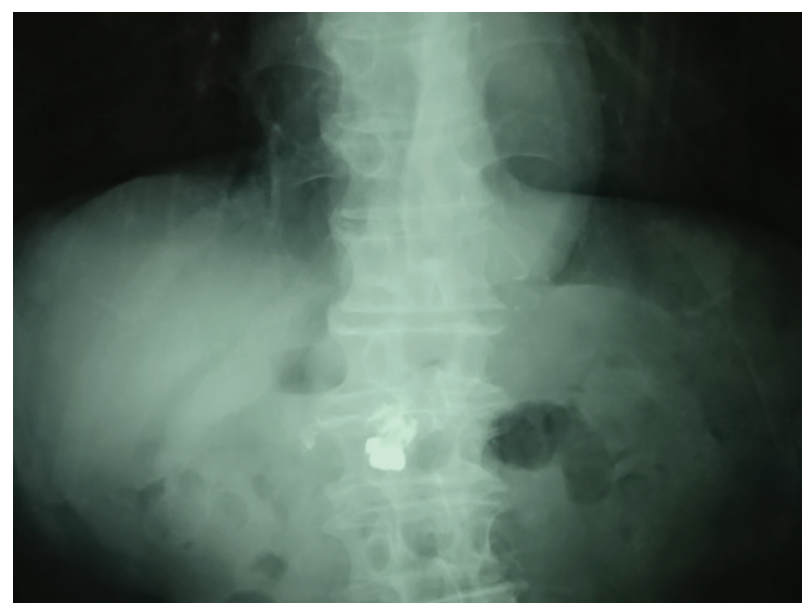

Figure 1. Abdominal X-ray demonstrating a crown and something in the stomach. 


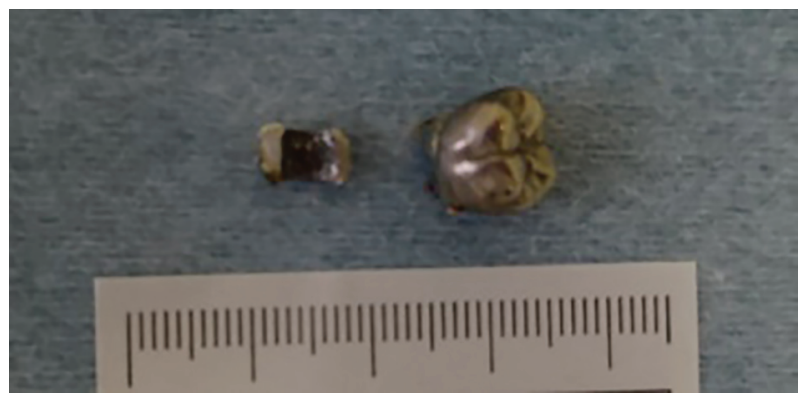

Figure 2. A crown and piece of tray were observed.

tray ingestion (Fig. 2).

\section{Discussion}

Ninety percent of ingested foreign bodies pass through the gastrointestinal tract uneventfully. Approximately 10\% necessitate endoscopic removal while only $1 \%$ will ever require surgical intervention. Impaction may occur at sites of anatomical or physiological narrowing such as the lower esophageal sphincter, ileocecal valve or areas of stricture formation. If the blunt object has passed into the stomach and is less than $6 \mathrm{~cm}$ in length and $2 \mathrm{~cm}$ in diameter, there is a $90 \%$ chance of spontaneous passage through the pylorus and ileocecal valve [4]. Passage of a sharp foreign body into the stomach requires immediate attempts at endoscopic retrieval, as the risk of perforation on reaching the ileocecal valve is approximately $35 \%$ [4]. In our case, we selected the urgent endoscopic retrieval, because the sharp foreign body was suspicious on the radiographic study.

Previously, accidental foreign body ingestion during a routine dental procedure was reported by different groups [1-3]. However, ingestion of multiple foreign bodies during a routine dental procedure is uncommon. Here, we describe a clinical case of accidental ingestion of concomitant crown and piece of tray. Previous reports about multiple foreign bodies include magnet [5], coin [6], and so on. Accidental ingestion of concomitant crown and a piece of tray is relatively rare.

The best option is to prevent accidents. Prevention for sharp objects such as root canal file is to use dental floss and then rolled up on the finger to allow ready recovery in case of deglutition or aspiration [7]. This is already practiced for other dental objects such as transpalatal arches [8], and bands [9]. However, in this case, this situation is not suitable, because the patient swallowed a piece of tray in addition to a crown. We think that dentist should not use old tray.

In conclusion, we describe a clinical case of accidental ingestion of concomitant crown and piece of tray in this case. Although multiple accidental ingestion is relatively rare, we should recognize this possibility in dental university hospital.

\section{Acknowledgments}

We are most grateful to the patient in this case report, for his reliance on our medical work and consent to be able to publish this case.

\section{Consent}

Written informed consent was obtained from the patient for publication of this case report and any accompanying images.

\section{Competing Interests}

The authors declare that they have no competing interests.

\section{Author Contributions}

The author YB has made the study design and concept, drafted the manuscript, and made critical review. YK has made a critical review for the manuscript and added comments to discussion. All authors read and approved the final manuscript.

\section{References}

1. Tiwana KK, Morton T, Tiwana PS. Aspiration and ingestion in dental practice: a 10-year institutional review. J Am Dent Assoc. 2004;135(9):1287-1291.

2. Zouros E, Oikonomou D, Theoharis G, Bantias C, Papadimitropoulos K. Perforation of the cecum by a toothpick: report of a case and review of the literature. J Emerg Med. 2014;47(6):e133-137.

3. Dhandapani RG, Kumar S, O'Donnell ME, McNaboe T, Cranley B, Blake G. Dental root canal treatment complicated by foreign body ingestion: a case report. Cases J. 2009;2(1):117.

4. Pavlidis TE, Marakis GN, Triantafyllou A, Psarras K, Kontoulis TM, Sakantamis AK. Management of ingested foreign bodies. How justifiable is a waiting policy? Surg Laparosc Endosc Percutan Tech. 2008;18(3):286-287.

5. Mirza MB, Bux N, Talat N, Saleem M. Multiple singing magnet ingestion leading to pressure necrosis of the small bowel. J Indian Assoc Pediatr Surg. 2015;20(2):90-91.

6. Upadhyaya EV, Srivastava P, Upadhyaya VD, Gangopadhyay A, Sharma S, Gupta D, Hassan Z. Double coin in esophagus at same location and same alignment - a rare occurrence: a case report. Cases J. 2009;2:7758.

7. Ratnaditya A, Ravuri S, Tadi DP, Kandregula CR, Kopuri RC, Pentakota VG. A simplified method of preventing implant hex drive from aspiration or accidental swallowing during stage two implant recovery. J Int Soc Prev Community Dent. 2014;4(Suppl 1):S23-25.

8. Absi EG, Buckley JG. The location and tracking of swallowed dental appliances: the role of radiology. Dentomaxillofac Radiol. 1995;24(2):139-142.

9. Dibiase AT, Samuels RH, Ozdiler E, Akcam MO, Turkkahraman H. Hazards of orthodontics appliances and the oropharynx. J Orthod. 2000;27(4):295-302. 